\title{
Sciendo
}

\author{
RESEARCH PAPERS FACULTY OF MATERIALS \\ SCIENCE AND TECHNOLOGY IN TRNAVA \\ SLOVAK UNIVERSITY OF TECHNOLOGY \\ IN BRATISLAVA
}

2018, Volume 26, Number 42

DOI 10.2478/rput-2018-0024

\section{INFLUENCE OF FINISH MILLING STRATEGIES ON THE TOOL WEAR}

\author{
Rudolf ZAUJEC, Peter POKORNÝ, František JURINA, Tomáš VOPÁT, \\ Vladimír ŠIMNA
}

\author{
SLOVAK UNIVERSITY OF TECHNOLOGY IN BRATISLAVA, \\ FACULTY OF MATERIALS SCIENCE AND TECHNOLOGY IN TRNAVA, \\ INSTITUTE OF PRODUCTION TECHNOLOGIES, \\ Ulica JÁNA BotTu 2781/25, 91724 TRNAVA, SLOVAK REPUBliC \\ e-mail: rudolf.zaujec@stuba.sk,peter_pokorny@stuba.sk, tomas.vopat@stuba.sk, \\ Frantisek.jurina@stuba.sk, vladimir.simna@stuba.sk \\ Received: 07.06.2018, Accepted: 13.07.2018, Published: 19.09.2018
}

\begin{abstract}
The article deals with the tool life of ball nose end mills during finish milling of weld deposit. The aim was to determine and compare the wear of ball nose end mill for different types of ball end milling strategies, as well as to specify particular steps of the measurement process. For tool life test, DMG DMU 85 monoBLOCK 5-axis CNC milling machine was used. In the experiment, the cutting speeds, feed rates, axial and radial depth of cut were constant. The coated cemented carbide was used as tool material. The cutting tool wear was measured on Zoller Genius 3s and laser Blum Micro Compact NT. The results show different achieved tool life of ball nose end mills depending on the finish milling strategy.
\end{abstract}

Key words

Wear, CAM, Milling, Tool, Finish

\section{INTRODUCTION}

Tool wear is generally considered as negative factor that accompanies each of machining process. This affects the cutting forces, cutting temperature and surface quality. The complete elimination of wear is not possible, but with a well-selected material of tool, coating and machining conditions it can be minimized. Taking into account these general conditions, research was focused on the impact of CAM strategies for wear and tool life of ball nose end mills. Research was focused on different finishing milling strategies in PowerMill software. In this case, principles of up and down-copying and up and down-contouring were used. Nowadays, research of wear of milling tools is not focused on one field. The position of the tool in relation to the machined surface (inclination angle) has a strong impact on the cutting forces (1-3). In (4) is an influence of the up and down-copying on tool wear and (5) on the 
surface roughness. Tian et al. (6) studied effect of cutting force to wear mechanisms for the down and up copying. Influence of inclination angles of cutting tool on wear of cutter after machining process are in (7) and (8). Impact of different types of hard machining materials on the tool wear of Ti-6Al-4V (9), Hastelloy C-22HS (10), 3Cr13Cu (11), compacted graphite iron and graphite iron (12). Zetek et al. (13) observed flank wear and measured cutting forces during the face milling of Inconel 718. They optimized size of edge radius and increased tool life about $20 \%$. Kasim et al. (14) found that notch wear was the predominant failure mode during end milling of Inconel 718. Begic-Hajdarevic et al. investigated the effect of cutting parameters on surface roughness in up- and down milling. In the major part of these publications, flank wear was the main criterion for evaluation of experiments. The article fastens on (15) which dealt with the roughing milling strategies for the same shape and material of workpiece.

\section{Cutting and workpiece material}

\section{METHODS}

The machining part was a die for forge intended for renovation in Fig. 2. For weld deposit, Oerlikon Fluxofil 54 welding material was used. It is a high-wear welded wire for welding with a hardness of approximately 42 HRC. Chemical composition of workpiece material is in Fig. 1

\begin{tabular}{|c|c|c|c|c|c|c|c|c|c|c|c|}
\hline $\mathrm{C}$ & $\mathrm{Mn}$ & $\mathrm{Si}$ & $\mathrm{P}$ & $\mathrm{S}$ & $\mathrm{Cr}$ & $\mathrm{Ni}$ & $\mathrm{Mo}$ & $\mathrm{Nb}$ & $\mathrm{Fe}$ & $\mathrm{W}$ & $\mathrm{Cu}$ \\
\hline 0.10 & 1.50 & 0.60 & - & - & 5.50 & - & 0.90 & - & - & - & - \\
\hline
\end{tabular}

Fig. 1 Chemical composition of workpiece material

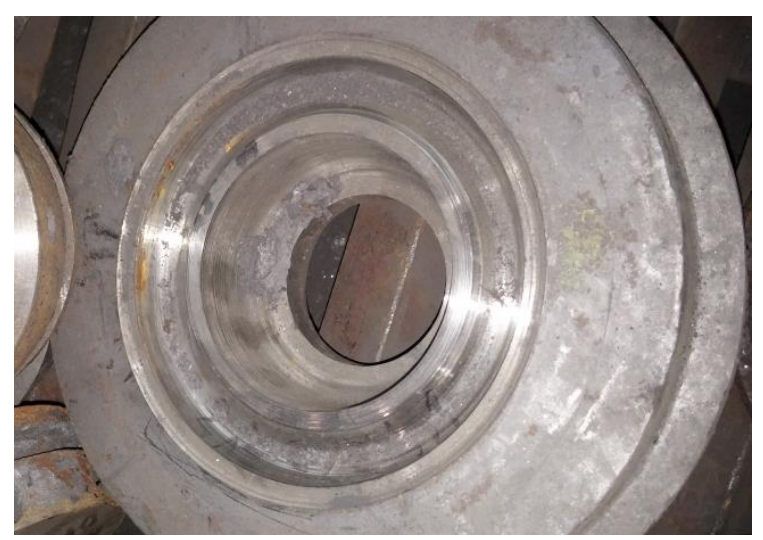

Fig. 1 Die for forge before renovation

The tool for cutting edge wear test was performed and selected for finishing of free form surfaces and applying multi-axis machining. The type of tool was a carbide ball nose end mill (Fig. 3) coated with TripleCoating Cr. It is a PVD coating consisting of three basic layers. The first layer is in direct contact with the tool and is made of titanium nitride (TiN). The second layer of the coating contains AlTiN and the last layer is the nanocomposite CrAlSiN. Table 1 shows the cutting condition used in experiment. Air coolant during the experiment was used. 


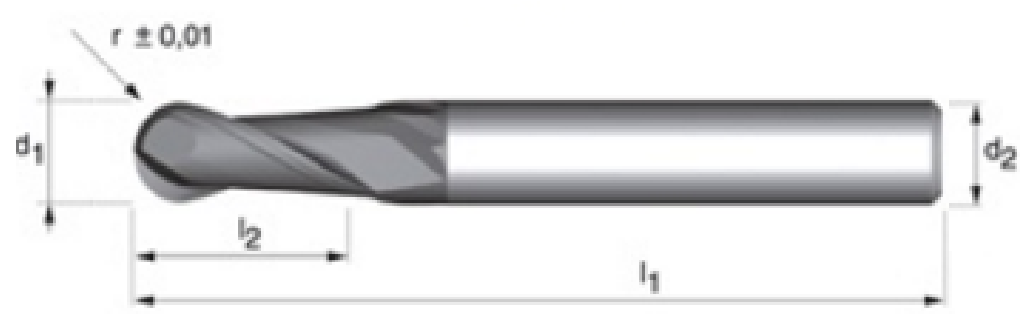

Fig. 3 Cutting tool used in experiments $d_{1}=8 \mathrm{~mm}, d_{2}=8 \mathrm{~mm}, r_{1}=4 \mathrm{~mm}, l_{2}=16 \mathrm{~mm}, l_{1}=100 \mathrm{~mm}$.

\begin{tabular}{|c|c|}
\hline Table 1: Cutting conditions \\
\hline Cutting speed & $350 \mathrm{~m} \cdot \mathrm{min}^{-1}$ \\
\hline Axial depth of cut & $0.2 \mathrm{~mm}$ \\
\hline Feed per tooth & $0.06 \mathrm{~mm}$ \\
\hline Radial deep of cut & $0.2 \mathrm{~mm}$ \\
\hline Spindle speed & $13926 \mathrm{~min}$ \\
\hline Feed rate & $1671 \mathrm{~mm} / \mathrm{min}$ \\
\hline
\end{tabular}

\section{D finish milling strategies}

For the 3D finishing strategies according to the machined area, it is evident that the wear interval will be on several parts of the cutting edge, however a substantial part of the machining can be defined on two surfaces 1 and 2 . The surface 1 is characterized by 93 degrees of descent and a second surface of $8.62^{\circ}$. We assume that the maximum wear of the flank wear will be achieved precisely by the machining in the places defined in Fig. 4.

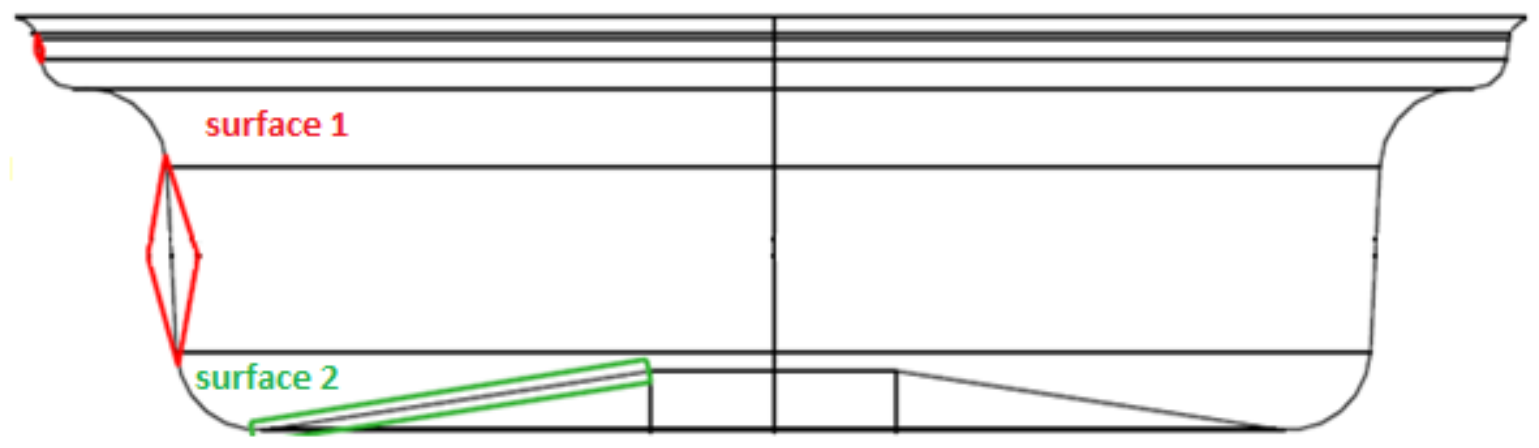

Fig. 4 Shape of die for forge with marked surface were is expectation for flank wear achieved

For descending, there were two situations in our cases ap $>$ apkrit $\wedge$ ap $<$ R. This case was determined at an angle of inclination of the area of $19^{\circ}$, since at that moment it was apkrit $=0.195774 \mathrm{~mm}$, i.e. it was smaller than our value of axial depth of cut. During higher angles of inclination, which means second case of calculation has been created according ap <apkrit ap <R. Therefore, we could create of the wear intervals as shown in Fig. 5. Calculations of Ref were based on $(16,17)$. Measurement VBmax was performed at both cutting edge locations with Refmax for area 1 and Refmin for area 2. 


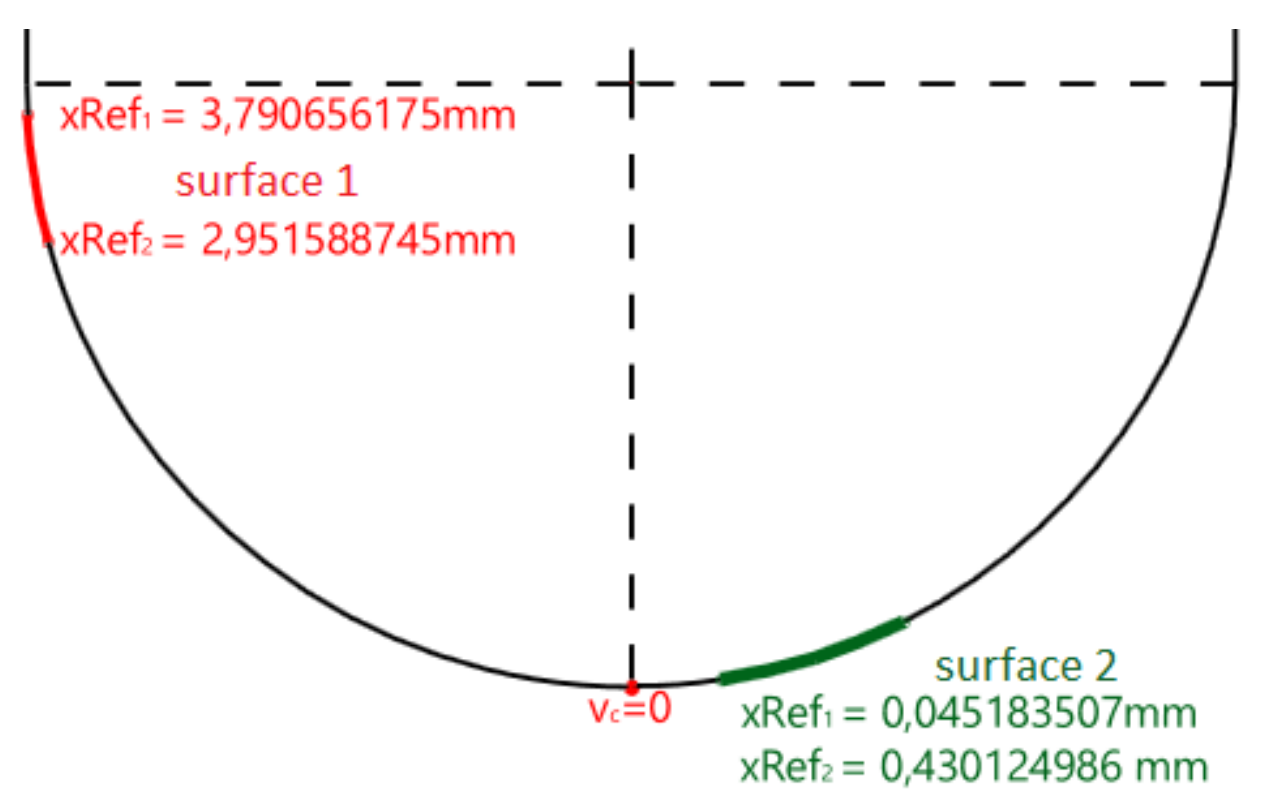

Fig. 5 Calculation of contact of cutting edge with workpiece

To compare 3D machining strategies, we focused on three different, and, at the same time, appropriate, finishing strategies of machining the workpiece shape. The machining strategies can be generated for the same boundaries with the same programming principle. The following experimental machining strategies were used:

- 3D Optimal $\mathbf{Z}$ - Fig. 6 the first used strategy in the experiment was 3D optimal $\mathrm{Z}$ with 2h: 05min: $44 \mathrm{~s}$ time path statistics. The applied path was generated in the contouring principle,

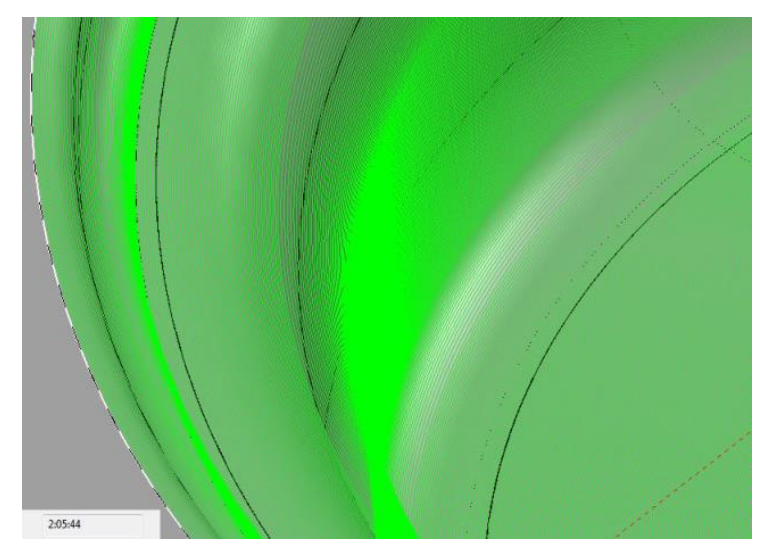

Fig. 6 Strategy Optimal Z

- 3D Radially - While the first machining strategy represents the principle of 3D contouring, 3D radially was in our case a representative of the copying strategy. In Fig. 7, we can see a programmed strategy with a detail of the path. There are interconnections set by using circular arcs. In terms of time, the given path is slightly less convenient than the previous one and its time was $2 \mathrm{~h}: 04 \mathrm{~min}: 56 \mathrm{~s}$. 


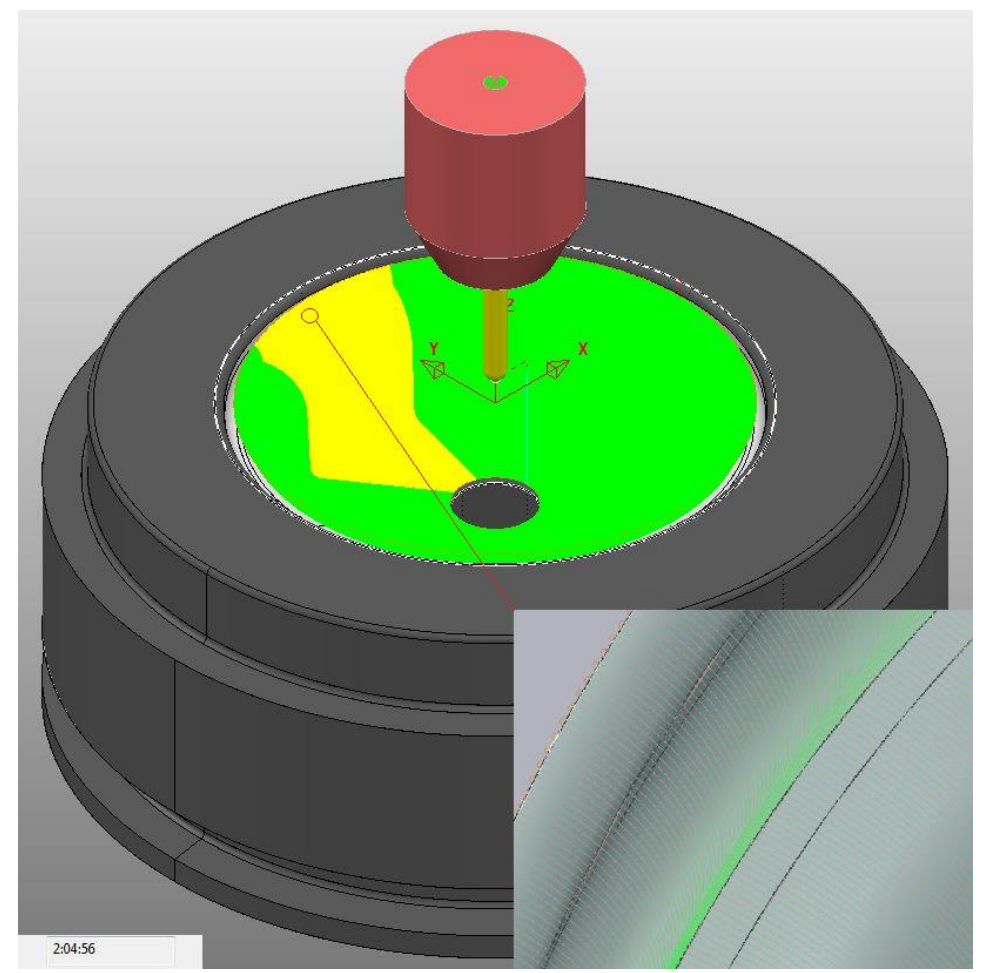

Fig. 7 Strategy 3D Radially

- 3D Steep and surface - The strategy differs from the previous ones. It is possible to use the program for finishing either the planar surfaces with their slight slope or the areas which that are steep (area 1 in Figure 4). Even with the last tested 3D machining strategy, based on 2h: 04min: $14 \mathrm{~s}$ statistics, it is confirmed that time comparison is unnecessary in that case. Fig. 8 illustrates a strategy of finishing a steep and surface with appropriate path details (yellow was for steep paths).

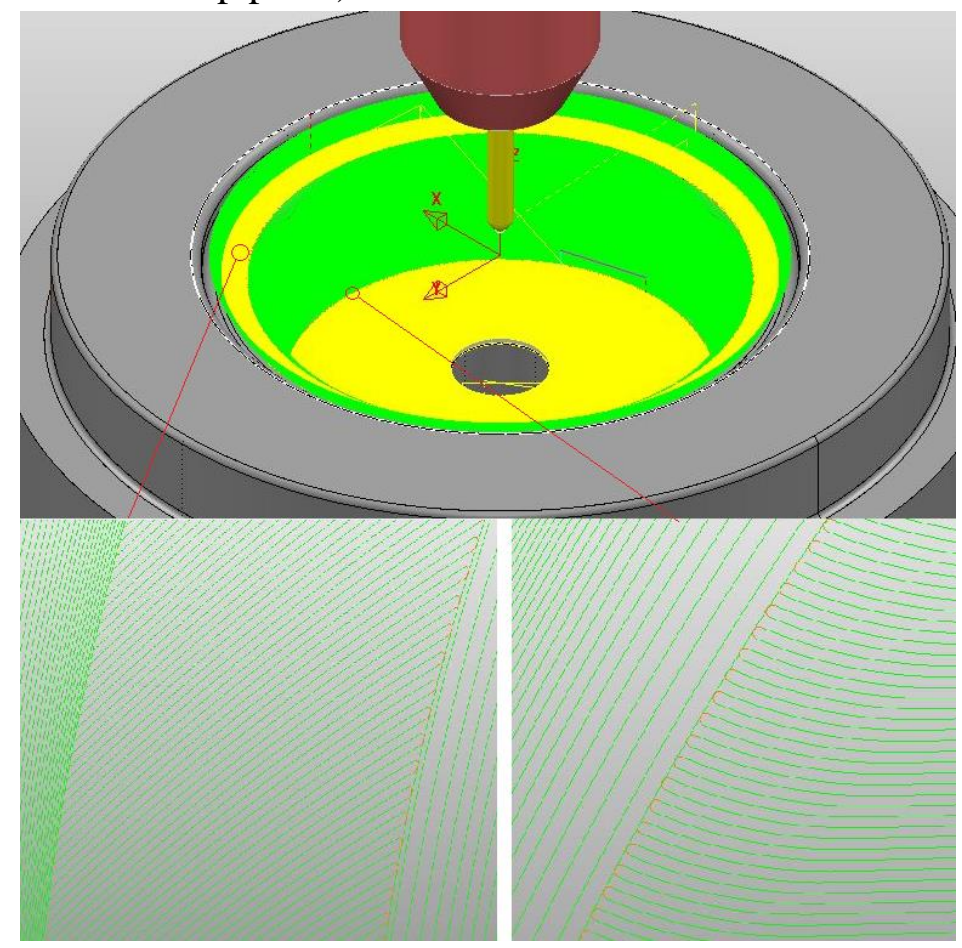

Fig. 8 Strategy Steep and surface 


\section{RESULTS}

As mentioned above, the VBmax measurement was performed at those parts of the cutting edge predicted by theoretical calculations. Values of the maximum flank wear can be seen in Table 2, but they were not achieved when machining the surface 1 where the effective cutting speed is greatest but on the area 2. The reason for greater wear on this part of the cutting edge can be seen in the significantly higher loads of the upper R4 and the lower R10. The second factor is of course the fact that the surface 2 is larger than the surface 1 .

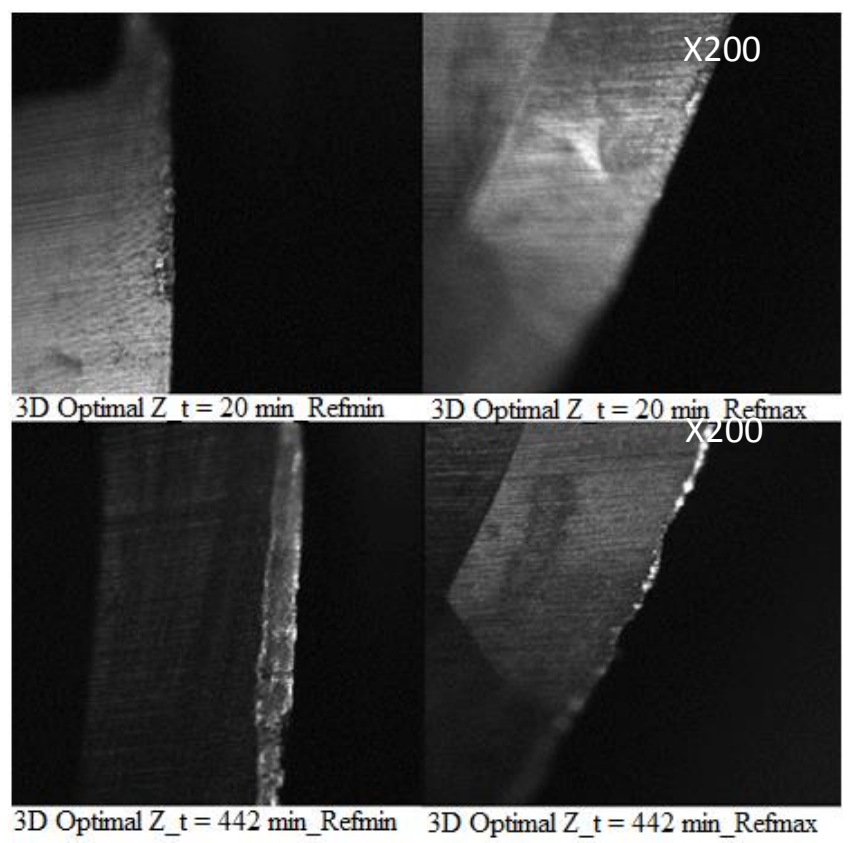

Fig. 9 3D Optimal Z - Flank wear after 20 minutes and last path

The wear on the main flank surface of the tool was a notch that was mainly due to Refmax in all the strategies used. The notches on the tool are formed especially at the point of contact of the cutting edge with the side of the chips. The wear is defined exactly where the air enters the machining area and at higher cutting speeds and the small depth of the cut is more pronounced. Most notably it was reflected in the 3D Optimal strategy as seen in Fig. 9. It is due to the fact that, with the contouring strategy, tool was milling constantly on the surface 1, which does not change the cutting edge contact with the surface and the high cutting speed was achieved. With 3D radial, the cutting edge and effective cutting speed kept changing. This fact caused the 3D strategy to radially achieve the worst wear parameters, as seen in Table 2 and Fig. 12.

3D Radially appeared to be relatively appropriate at the large inclination of the surface 2 where the wear was significantly better distributed than in the Optimized Z. However, the transition areas between the surfaces (undercut, radius) had a negative effect on VBmax in the Refmin. With 3D radial, we noticed the chipping of the cutting edge, which was attributed to an uneven load on the tool in transitions, especially over a radius of $4 \mathrm{~mm}$. 


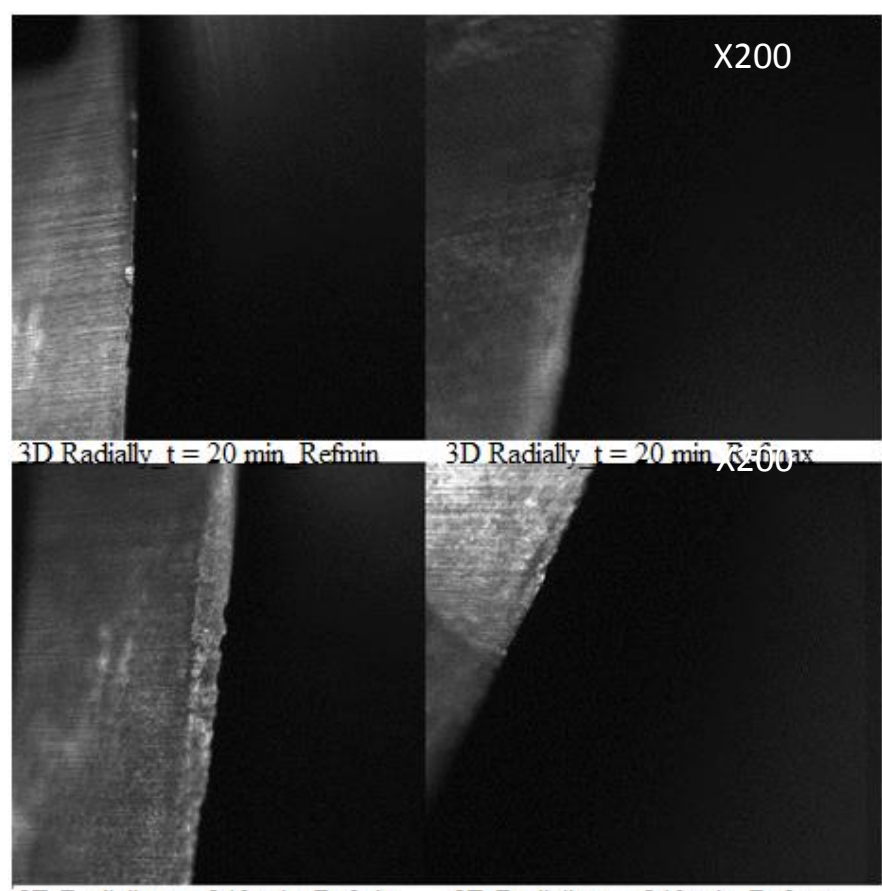

Fig. $13 D$ Radially - Flank wear after 20 minutes and last path

\begin{tabular}{|c|c|c|c|c|c|c|c|c|}
\hline \multicolumn{9}{|c|}{ Flank wear during 3D strategies } \\
\hline \multicolumn{3}{|c|}{ B3D Optimal Z } & \multicolumn{3}{|c|}{ 3D Radially } & \multicolumn{3}{|c|}{ Steep and surface } \\
\hline & Ref_min & Ref_max & & Ref_min & Ref_max & & Ref_min & Ref_max \\
\hline $\begin{array}{c}\mathbf{t} \\
(\mathrm{min})\end{array}$ & $\begin{array}{c}\text { VB } \\
(\mathrm{mm})\end{array}$ & $\begin{array}{c}\mathrm{VB} \\
(\mathrm{mm})\end{array}$ & $\begin{array}{c}\mathbf{t} \\
(\mathrm{min})\end{array}$ & $\begin{array}{c}\mathrm{VB} \\
(\mathrm{mm})\end{array}$ & $\begin{array}{c}\mathrm{VB} \\
(\mathrm{mm})\end{array}$ & $\begin{array}{c}\mathbf{t} \\
(\mathbf{m i n})\end{array}$ & $\begin{array}{c}\mathrm{VB} \\
(\mathrm{mm})\end{array}$ & $\begin{array}{c}\mathrm{VB} \\
(\mathrm{mm})\end{array}$ \\
\hline 10 & 0.0380 & 0.01 & 10 & 0.0230 & 0.023 & 10 & 0.0150 & 0.0210 \\
\hline 20 & 0.0450 & 0.032 & 20 & 0.0325 & 0.0275 & 20 & 0.0210 & 0.0275 \\
\hline 40 & 0.0475 & 0.0325 & 40 & 0.0355 & 0.0305 & 40 & 0.0210 & 0.0330 \\
\hline 60 & 0.0475 & 0.0405 & 60 & 0.0390 & 0.0335 & 60 & 0.0210 & 0.0355 \\
\hline 109 & 0.0570 & 0.0475 & 120 & 0.0575 & 0.0375 & 115 & 0.0395 & 0.0355 \\
\hline 159 & 0.0580 & 0.0510 & 180 & 0.0810 & 0.0420 & 180 & 0.0435 & 0.0395 \\
\hline 218 & 0.0635 & 0.0560 & 240 & 0.1060 & 0.0480 & 230 & 0.0845 & 0.0410 \\
\hline 328 & 0.0895 & 0.0570 & & & & 346 & 0.1420 & 0.0435 \\
\hline 442 & 0.1315 & 0.0640 & & & & & & \\
\hline
\end{tabular}




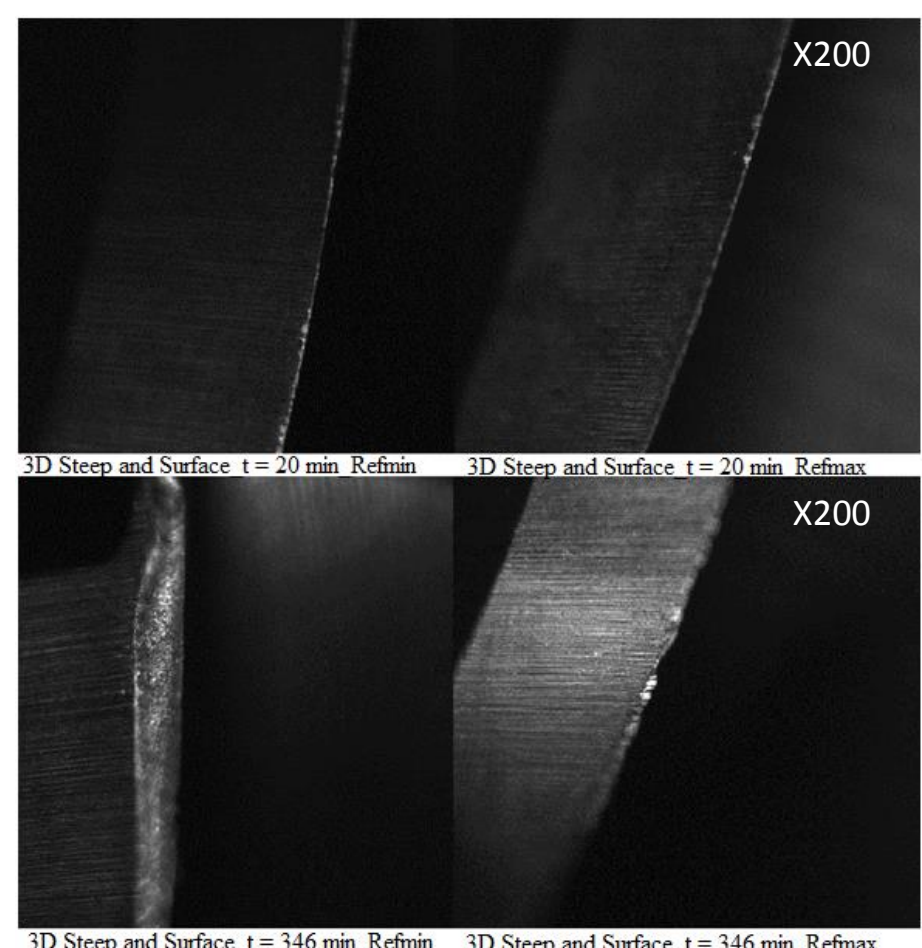

Fig. $113 D$ Steep and surface - Flank wear after 20 minutes and last path

The steep and surface was the second best finish milling strategy in terms of both wear and quality of the workpiece surface, which could be expected, because it was combination of the previous two. The principle of copying machining at a different angle in the cutting direction $\left(30^{\circ}\right.$ at $3 \mathrm{D}$ Radially it was $\left.90^{\circ}\right) 4 \mathrm{~mm}$ radius at the top edge in Fig. 4 caused the Refmin to achieve even flank wear without chipping in the cutting edge. Although the flank wear was worn in a suitable form, the copying principle caused again the VB values was higher than the Optimal Z. Comparison of the surfaces with the naked eye principle confirmed the same results of finish milling strategies like tool wear.

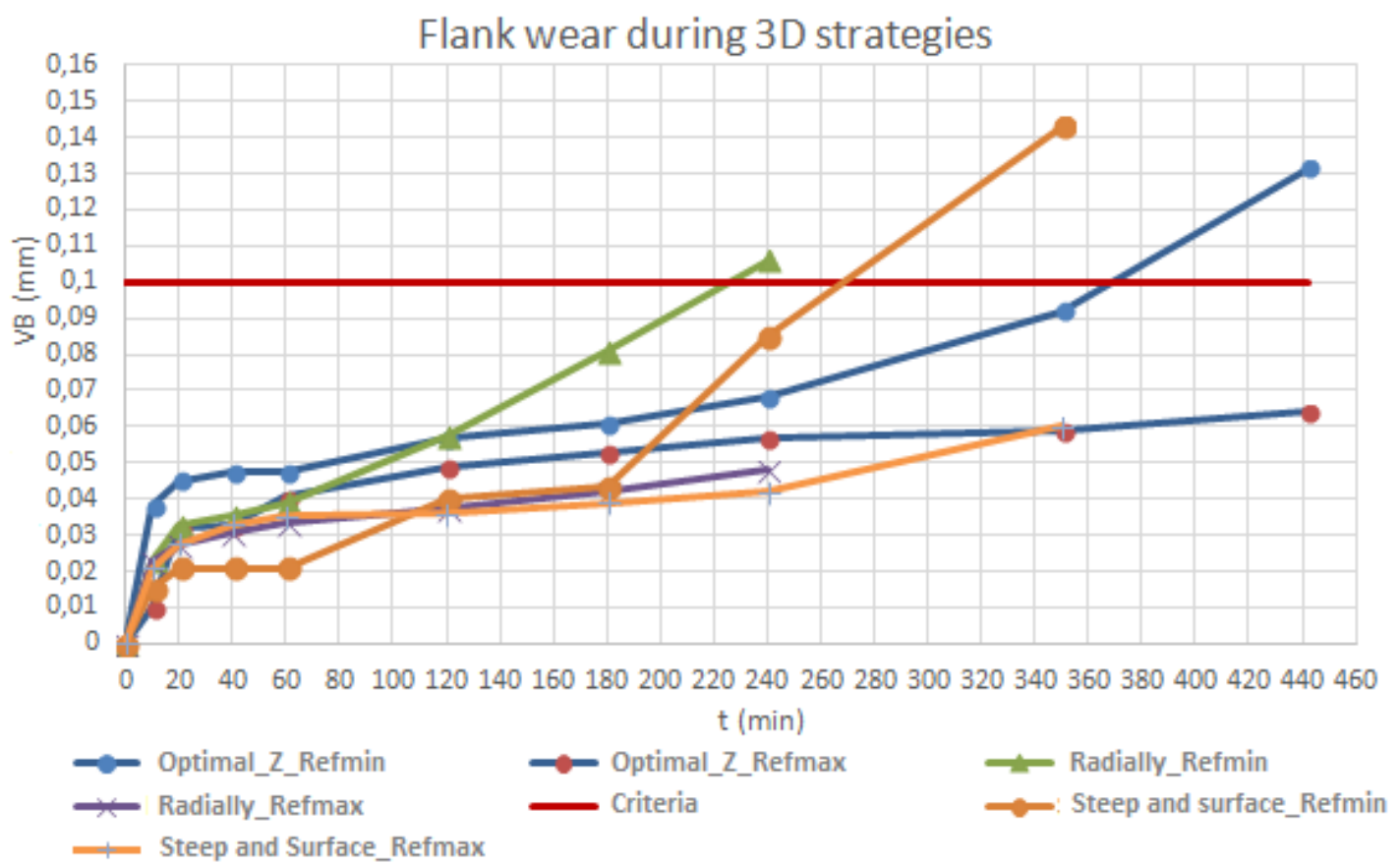

Fig. 12 Flank wear during 3D strategies 


\section{CONCLUSION}

In the experiment, we investigated the different principles of 3D finishing strategies for tool wear. Based on the most commonly used principles for milling with ball nose end mill, the strategies were tested. The contouring principle represented a 3D Optimal strategy where the best results of flank wear were achieved. We found that the used CAM strategy has a significant impact on the surface quality and durability of the cutting tools, as confirmed by the HKS Forge practical experiment. Furthermore, was found that the Triplecoating $\mathrm{Cr}$ coating is suitable for use on weld deposit up to $55 \mathrm{HRC}$, even at higher cutting speeds than commonly recommended for a given material grade. The experiment was based on the roughing principles of milling the forging dies. In this experiment, we found the most appropriate 3D finishing strategy. In further experiments, we will test 3D Optimal for 4 - 5 D machining applications. We want to determine the impact of multi-axis machining on the durability of ball nose end mills. In further experiments, we expect to increase the tool life and durability of cutting tools.

\section{Acknowledgement}

The article was written with the support of the project of VEGA grant agency of the Ministry of Education, Science, Research and Sport of the Slovak Republic and Slovak Academy of Sciences, No. 1/0097/17: "The research of novel method for cutting edge preparation to increase the tool performance in machining of difficult-to-machine materials", project and APVV Project of Slovak Research and development Agency of the Ministry of Education, Science, Research and Sport of the Slovak Republic, No. APVV-16-0057: "Research into the Unique Method for Treatment of Cutting Edge Microgeometry by Plasma Discharges in Electrolyte to Increase the Tool Life of Cutting Tools in Machining of Difficult-to-Machine Materials."

\section{References:}

1. M. FONTAINE, A. DEVILLEZ, A. MOUFKI, D. DUDZINSKI. 2007. Modeling of cutting forces in ball end milling with tool surface inclination, Part II. Influence of cutting conditions, run-out, ploughing and inclination angle. J. Mater. Process. Technol., 189(1-3), pp. 85-89.

2. A. DAYMI, M. BOUJELBENE, J.M. LINARES, E. BAYRAKTAR, A. BEN AMARA. 2009. Influence of workpiece inclination angle on the surface roughness in ball end milling of the titanium alloy Ti-6Al-4V. J. Achiev. Mater. Manuf. Eng., 35(1), pp. 79-86.

3. C.E.H. VENTURA, A. HASSUI. 2013. Evaluation of static cutting forces and tool wear in HSM process applied to pocket milling. Int. J. Adv. Manuf. Tech. 65, pp. 1681-1689.

4. T. VOPÁT, J. PETERKA, V. ŠIMNA, M. KURUC. 2015. The influence of different types of copy milling on the surface roughness and tool life of end mills. Procedia Engineering, Vol. 100, pp. 868-876. ISSN 1877-7058

5. D. BEGIC-HAJDAREVIC, M. KULENOVIC, A. CEKIC. 2014. Experimental study on the high speed machining of hardened steel. Procedia Engineering, Vol. 69, pp. 291-295.

6. T. XIANHUA, Z. JUN. 2013. Effect of cutting speed on cutting forces and wear mechanisms in high-speed face milling of Inconel 718 with Sialon ceramic tools. Int. J. Adv. Manuf. Tech. 69, pp. 2669-2678.

7. C. XIAOXIAO, Z. JUN, H. SHIGUO. 2013. Effects of inclination angles on geometrical features of machined surface in five-axis milling. Int. J. Adv. Manuf. Tech. 65, pp. 1721-1733,

8. H. SCHULZ, S. HOCK. (1995). High-speed milling of die and moulds - cutting conditions and technology. Annals of the CIRP, 44, pp. 35-38.

9. Z. SONG, L. JIAN-FENG. 2010. Tool wear criterion, tool life, and surface roughness during high speed steel end milling Ti-6Al-4V. J. Zhejiang Univ. Sci., A. 8, pp. 587-595. 
10. K.A. KADIRGAMAA, A. ABOU-EL-HOSSEINB. 2011. Tool life and wear mechanism when machining Hastelloy C-22HS. Elsevier Wear, 270, pp. 258-268.

11. Q. XINYI, L. PENGNAN. 2014. Study on serrated chip formation and tool wear of cermet tools for milling stainless steel 3Cr13Cu. Int. J. Adv. Manuf. Tech., 77, pp. 461-467.

12. M.B. DA SILVA, V.T.G. 2011. Naves, Analysis of wear of cemented carbide cutting tools during milling operation of gray iron and compacted graphite iron. Wear, 271, pp. 2426-2432.

13. M. ZETEK. I. CESAKOVA, V. SVARC. 2014. Increasing Cutting Tool Life when Machining Inconel 718. Procedia Engineering, Vol. 69, pp. 1171-1179.

14. M.S. KASIMA. C.H. CHE HARONB, J.A. GHANIB et al. 2013. Wear mechanism and notch wear location prediction model in ball nose end milling of Inconel 718. Wear, 302(1-2).

15. J. URMINSKÝ, R. ZAUJEC. 2018. Analysis of hardfacing and milling of forging die by CAx technologies. Materials Science Forum, Vol. 919, s. 354-361. ISSN 0255-5476

16. C.C. TAI, K.H. FHU. 1994. A predictive force model in ball-end milling including eccentricity effects. Int. J. Mach. Tools Manufact. 34, pp. 959-979.

17. J. PETERKA. 1997. Rozbor geometrie a kinematiky kopírovacieho frézovania. (Analysis of the geometry and kinematics of copy milling.) In: Vedecké práce MTF STU in Trnava, 5, pp. 53- 58. ISBN 80-227-1005-9

\section{ORCID:}

Tomáš Vopát 0000-0002-6489-9014

Vladimír Šimna 0000-0001-7489-2441 